\title{
Commuters remain stoical in face of terrorist attacks
}

\author{
Londoners are coping relatively \\ well after the terrorist attacks \\ of 7 July, psychologists say. \\ In a survey of 1,010 \\ Londoners, $31 \%$ reported \\ symptoms of substantial stress \\ - a number that is somewhat \\ lower than has been found in \\ other countries following \\ terrorist attacks. The study \\ was conducted after the 7 July \\ bombings but before the failed \\ attacks of 21 July. \\ Muslims, who may have felt \\ singled out in the search for \\ perpetrators, grouped with \\ those who had struggled to \\ contact family or friends \\ immediately after the \\ bombings as the people who \\ experienced the most stress. \\ The findings appeared
}

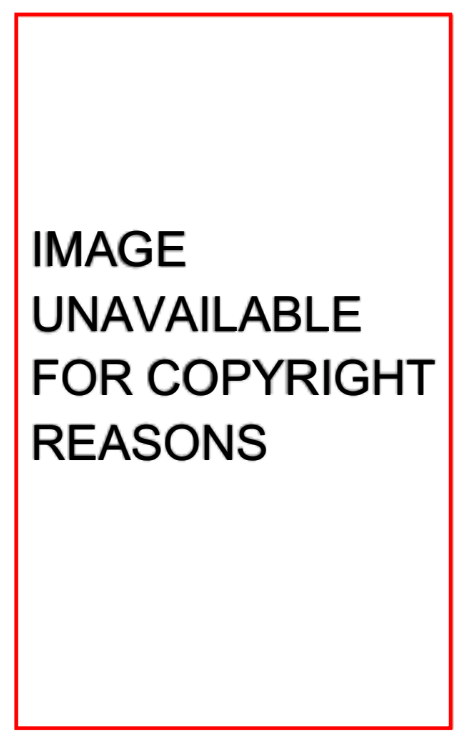

Very few of those caught in the London bombings want counselling. online last week in the $B M J$

(G. J. Rubin et al.doi:10.1136/ bmj.38583.728484.3A; 2005).

After the 11 September 2001 terrorist attacks in the United States, $44 \%$ of the people surveyed in New York and Washington reported feeling substantial stress.

Although the London attack was on a much smaller scale, Londoners may have fared better because they have a history of dealing with terrorism, says Neil Greenberg, a trauma expert at King's College London and coauthor of the recent study.

In New York, $11 \%$ of those questioned went on to develop post-traumatic stress disorder (PTSD) within one to two months. Psychologists have found even higher rates of PTSD in the Middle East (as much as $40 \%$ in one study) where repeated violence creates an ongoing sense of threat.

Greenberg says it is too early to tell if Londoners are suffering from PTSD, but his team's results suggest that this is unlikely. "If one third were substantially stressed less than two weeks after the bombings, then it is reasonable to think that the level of PTSD will be less than this," he says. "We know that people's distress levels fall rapidly with time."

The team plans to interview the same people in six months to see how they are doing. Jennifer Wild 